Original article

Received: 23 May 2017 / Accepted: 9 November 2017

\title{
INVESTIGATION OF STABILITY OF PRECISE GEODETIC INSTRUMENTS USED IN DEFORMATION MONITORING
}

\author{
Marek Woźniak, Waldemar Odziemczyk \\ Faculty of Geodesy and Cartography, Warsaw University of Technology
}

\begin{abstract}
Monitoring systems using automated electronic total stations are an important element of safety control of many engineering objects. In order to ensure the appropriate credibility of acquired data, it is necessary that instruments (total stations in most of the cases) used for measurements meet requirements of measurement accuracy, as well as the stability of instrument axis system geometry. With regards to the above, it is expedient to conduct quality control of data acquired using electronic total stations in the context of performed measurement procedures.

This paper presents results of research conducted at the Faculty of Geodesy and Cartography at Warsaw University of Technology investigating the stability of "basic" error values (collimation, zero location for $V$ circle, inclination), for two types of automatic total stations: TDA 5005 and TCRP 1201+. Research provided also information concerning the influence of temperature changes upon the stability of investigated instrument's optical parameters. Results are presented in graphical analytic technique. Final conclusions propose methods, which allow avoiding negative results of measuring tool-set geometry changes during conducting precise deformation monitoring measurements.
\end{abstract}

Keywords: geometry of instrument's axis, instrument stand, deformation monitoring, geodetic control measurements

\section{Monitoring of deformations}

In order to provide safety of controlled objects, it is necessary to perform continuous monitoring of their technical state. Geodetic measurements are an important element of such monitoring. It can be done with a wide range of measuring techniques, such as classical geodetic measurements, satellite observations, photogrammetry registration, laser scanning, inclinometry and others.

Classical geodetic methods are considered as the most reliable. They are an important element of deformation measurements for various objects. In comparison to satellite measuring methods (also widely used), they provide higher precision and 
are independent of direct satellite signal availability. Geodetic methods allow relating measurement results to reference points, which are not affected by the displacement of the monitored object. An example of deformation monitoring system using geodetic methods is described in Michel V. et al. (2003).

An important condition of obtaining highest accuracy results is an application of proper measuring instruments. Usually, precise motorized total stations are used in typical geodetic measurements.

Authors of this paper attempted to analyse the most important factors in 3D deformation measurements conducted with precise total stations.

As geodetic monitoring is performed over a long period of time, it is very important to work out how the changing condition of the object affect the stability of instrument geometry. The stability of instrument geometry we consider as:

- stability of geometrical axis of total station,

- stability of instrument position during the course of measuring session,

- stability of vertical axis and system of tilt compensation,

- stability of the azimuth orientation.

The geometry of total station axis is defined as a part of the calibration procedure, which allows determining the instrument errors, such as Hz-collimation, V-collimation, inclination error or compensator error. Usually, calibration is performed with special, device-specific calibration software. Proper calibration of the measuring instrument allows internal numerical correction of the observation results, as long as the calibration parameters are up to date.

The instrument position is represented by the main point of the instrument defined by the intersection of the vertical rotation axis and the horizontal rotation axis. Stability of instrument position, vertical axis and azimuth orientation depends on type and quality of the instrument stand.

\section{Measurement test}

In the course of investigations conducted by Faculty of Geodesy and Cartography of Warsaw University of Technology authors analysed several types of instrument errors of precise total stations. Especially $\mathrm{Hz}$-collimation, $\mathrm{V}$-collimation and tilt compensator errors were taken into consideration.

We also analysed the stability of total station spatial orientation. We conducted our investigation for two total stations TDA5005 and TCRP1201+ of Leica Geosystems (Fig. 1). Both instruments were mounted on a standard wooden stand during measurements. Quality of the stand is particularly important when motorized total station is used due to torque caused by automatic motion start and stop. Dynamic changes of stand geometry with working total station were investigated by C. Depenthal (2004).

TDA5005 is a precise electronic total station dedicated for industrial application. Internal instrument software base on TPS1000 system. Its accuracy as specified by the manufacturer are \pm 0.15 mgon for angle measurements and $\pm(0.2 \mathrm{~mm}+2 \mathrm{ppm})$ for distance measurements. Test of accuracy of this instrument is presented in (Gottwald et al. 2011). TDA5005 applicability for deformation monitoring was a subject of research published by (Woźniak M. 2006). TCRP1201+ is an instrument of more recent generation. Its software based on TPS1200 system enables easier access to data storage and instrument settings. Both total stations are fitted with servos and 
ATR systems. Improved ATR of TCRP1201+ is described in (Kirchner $H$., Stempfhuber W. 2008).

To obtain necessary data, series of measurements were conducted. Measurements were made using automatic mode. The process of measurement was controlled by special software run on a PC connected with total station via a serial port. The controlling software (TC-calc) has been developed by authors and was presented in (Odziemczyk W., Woźniak M. 2008) and (Odziemczyk W. 2012).

Measurements were performed on the skylight of the Main Hall of the Warsaw University of Technology. The course and results of measurements were described by (Wożniak M. et al. 2008), (Odziemczyk W., Woźniak M. 2009) or (Odziemczyk W. 2014). Construction of skylight consists of two roof coats, which causes large temperature fluctuation during sunny days. In such conditions analysed values and their impact on the measurement results were much higher and easier to notice. Temperature was the only parameter analysed as a factor causing changes in measured values. The air pressure has some influence to measured distances but distances were not analysed in the research. Another factor which wasn't taken into consideration was humidity. Humidity can have some impact to wooden stand geometry but in the closed space of the inter-roof changes of humidity were strictly (reversely) connected with the changes of temperature (Pearson correlation coefficient close to -1 ).

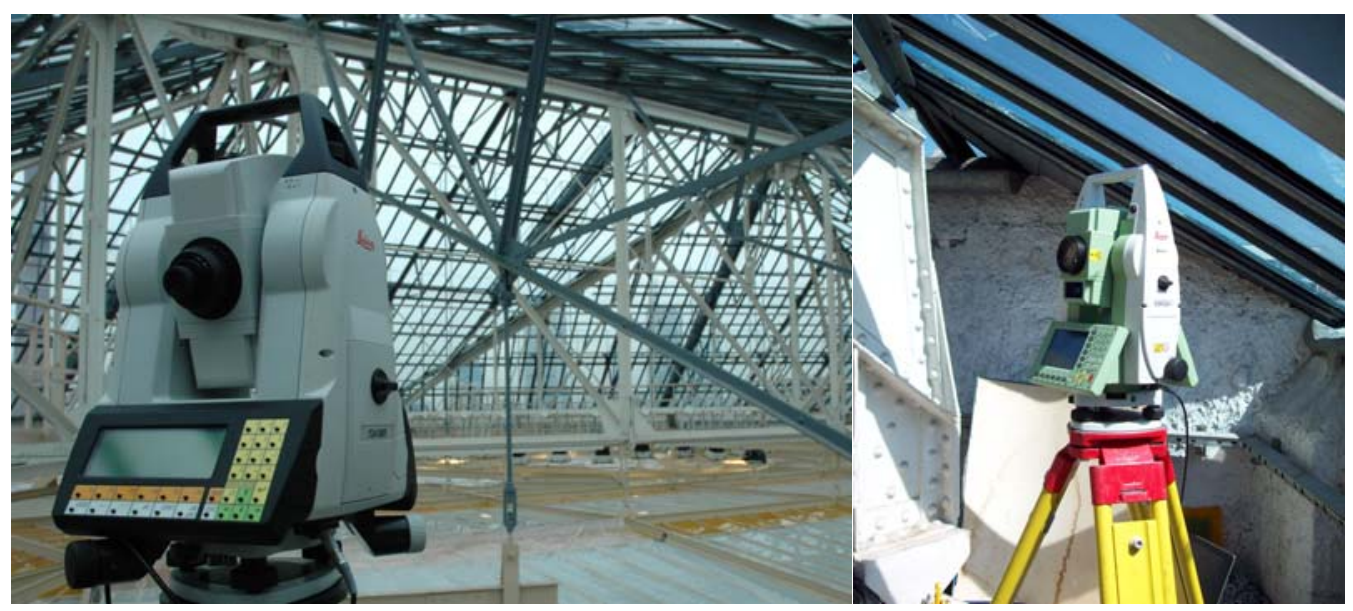

Fig. 1. Total stations TDA5005 (left) and TCRP1201+ (right) on the test object

\section{Measurement I (TDA5005)}

The measurement was conducted over the course of one day. The maximal temperature amplitude reached $22.8^{\circ} \mathrm{C}$. Detailed chart of temperature changes during measurement is presented in Fig. 3. Configuration of instrument station (St) and measured points if shown in figure 2 . Four points $(1,2,3,7)$ were observed during measurement I. Instrument station as well as points 1 and 7 are located on concrete bearings of the skylight construction and were assumed as constant. Points 2,3 and 4 were mounted on steel skylight construction. Measurement cycles were performed every $30 \mathrm{~min}$. Each cycle consisted of two single measurements made in two faces, so the effect of instrumental errors (Hz-collimation, V-collimation) could be easily eliminated during data processing. The time delay between two measurements of the same point in one cycle was about $1 \mathrm{~m} \mathrm{45s}$, which allowed us to neglect point movements and temperature changes during a cycle. Two face measurement allows us also to calculate values of instrumental errors, which deliver important information 
about the vulnerability of total station parameters to the temperature changes. Changes of Hz-collimation and V-collimation are shown in Fig. 4 and 5.

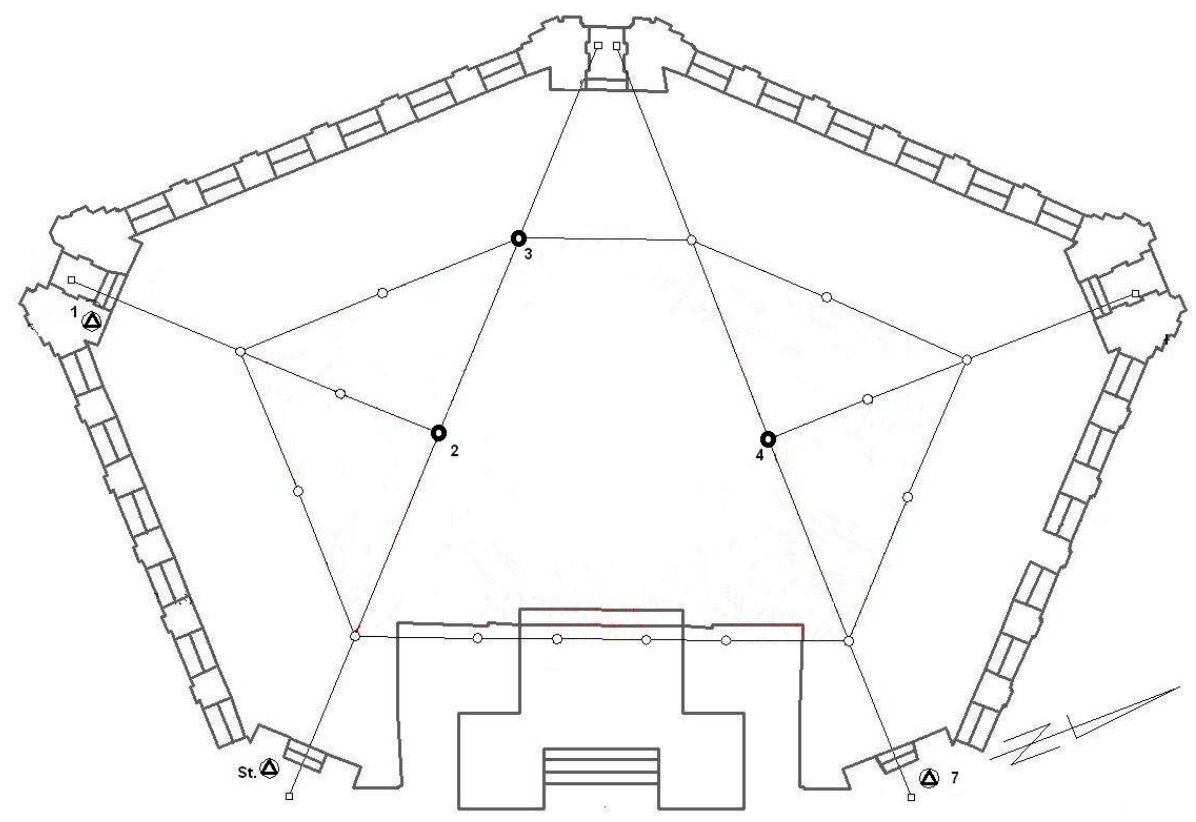

Fig. 2. Location of the station and control points during measurement I

Changes of instrument orientation calculated using measurements to fixed points are shown in Fig. 6.

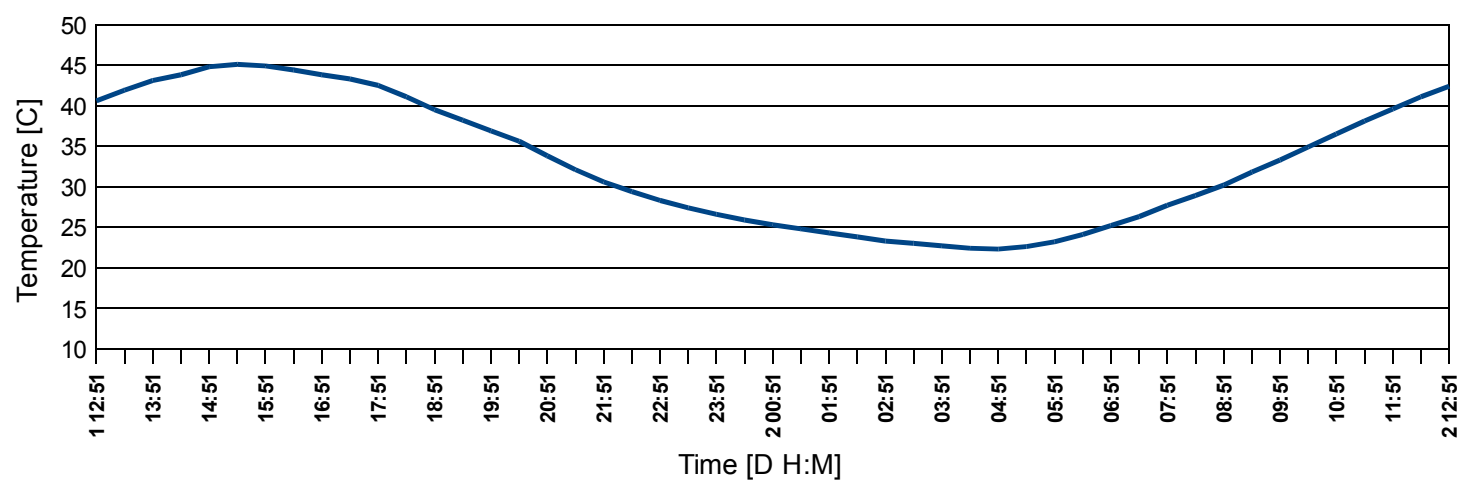

Fig. 3. Changes of temperature during measurement I

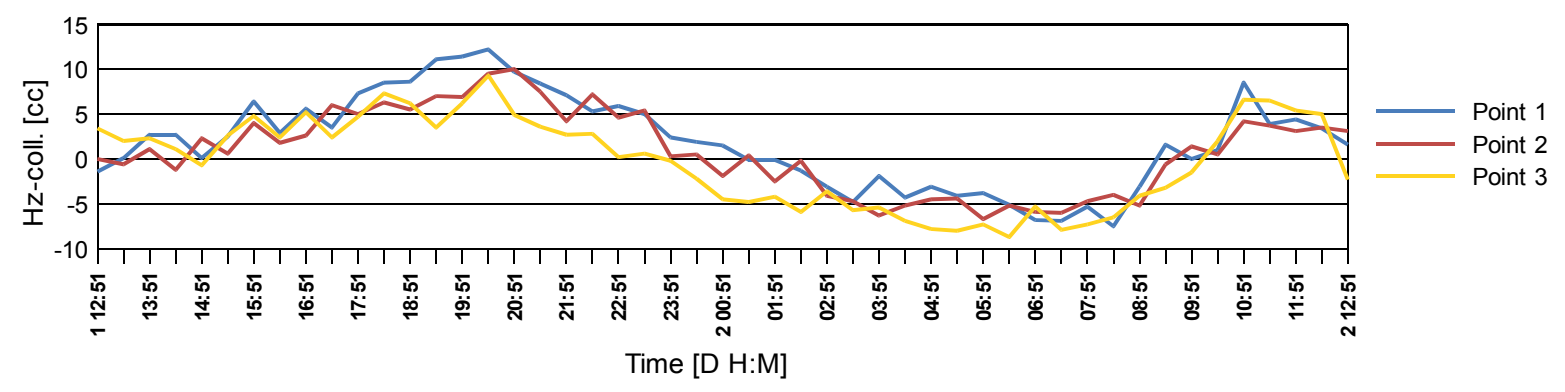

Fig. 4. Changes of Hz-collimation - measurement I 


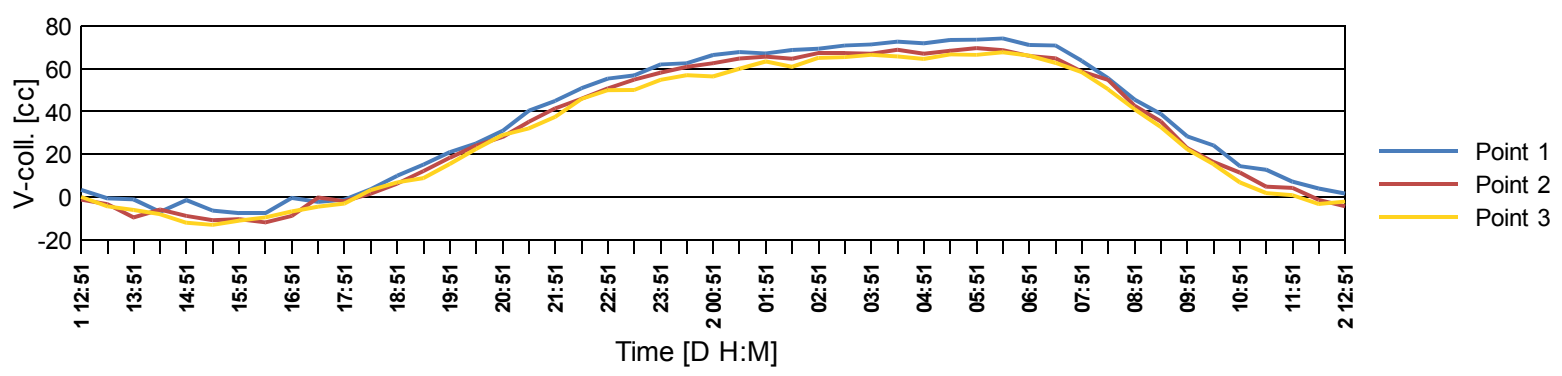

Fig. 5. Changes of V-collimation - measurement I

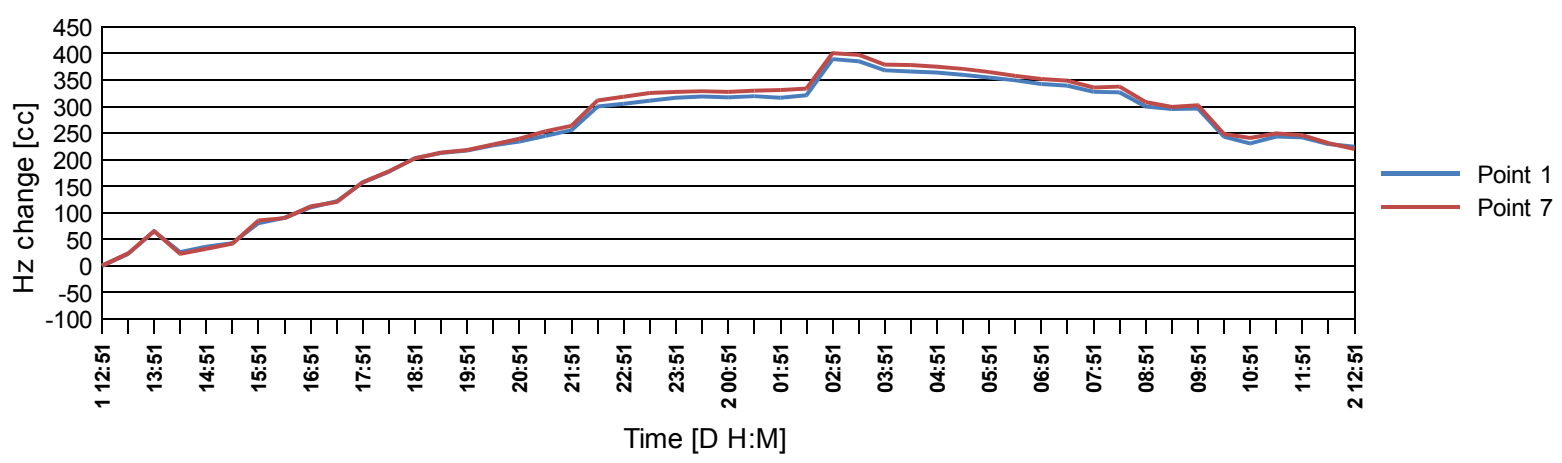

Fig. 6. Changes of instrument orientation during measurement I

Changes of Hz-collimation did not exceed 0.002gon. Changes of V-collimation are bigger and reached about $0.01 \mathrm{gon}$. Charts of $\mathrm{Hz}$ - and $\mathrm{V}$-collimation changes were already presented in (Odziemczyk W., Woźniak M. 2009).

Changes of orientation were acquired as changes of horizontal angles to constant points 1 and 7 and they appeared to be very large. Part of the change (Fig. 6) is correlated with temperature but there is also constant drift during the whole measurement period.

To determine the correlation between measured values and temperature we made an additional analysis. Charts shown in fig. 7, 8 and 9 present value of Pearson correlation coefficient. The horizontal axis represents the time shift in hours.

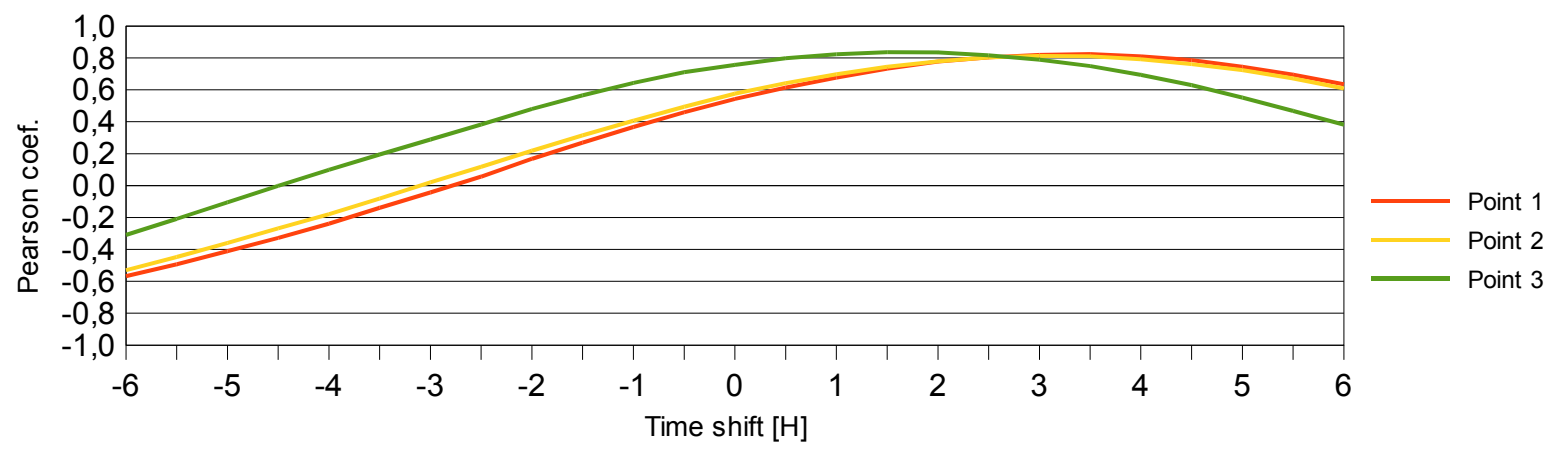

Fig. 7. Correlation between Hz-collimation and temperature (Pearson coefficient) 


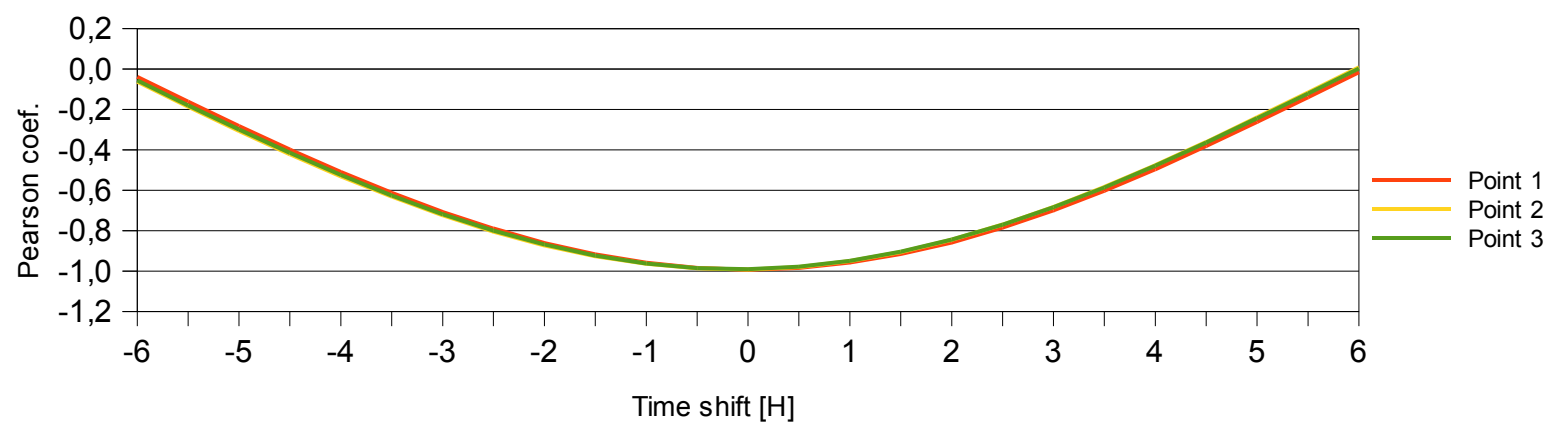

Fig. 8. Correlation between V-collimation and temperature (Pearson coefficient)

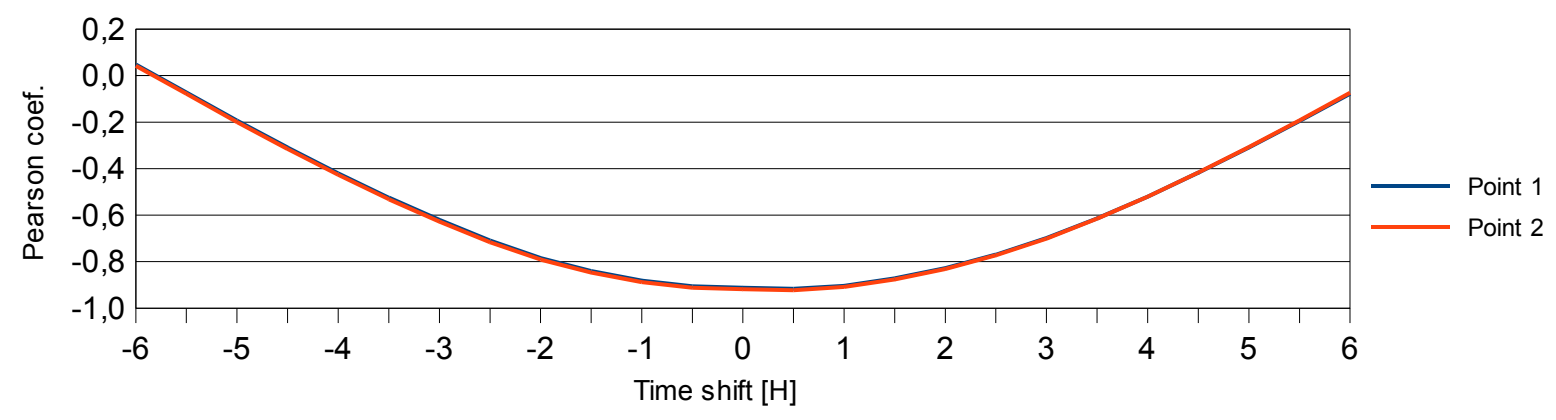

Fig. 9. Correlation between orientation changes and temperature (Pearson coefficient)

As it can be seen, all the analysed values are strongly correlated with temperature (Pearson coefficient close to 1). In the case of Hz-collimation, there is about 2 hour shift visible. It differs slightly between various targets. This phenomenon is difficult to explain at the moment of preparing this paper.

\section{Measurement II (TCRP1201+)}

The measurement was taken during a 1-day session. The range of temperature changes reached $25.1^{\circ} \mathrm{C}$. A detailed chart of temperature changes during measurement is shown in figure 10. Location of the station and measured points were similar to those applied for measurement I (Fig. 2a). Organisation of measurement and data processing was also similar. Due to better parameters of TCRP1201+ servos time delay between measurement of the same point was shorter (1m 15s).

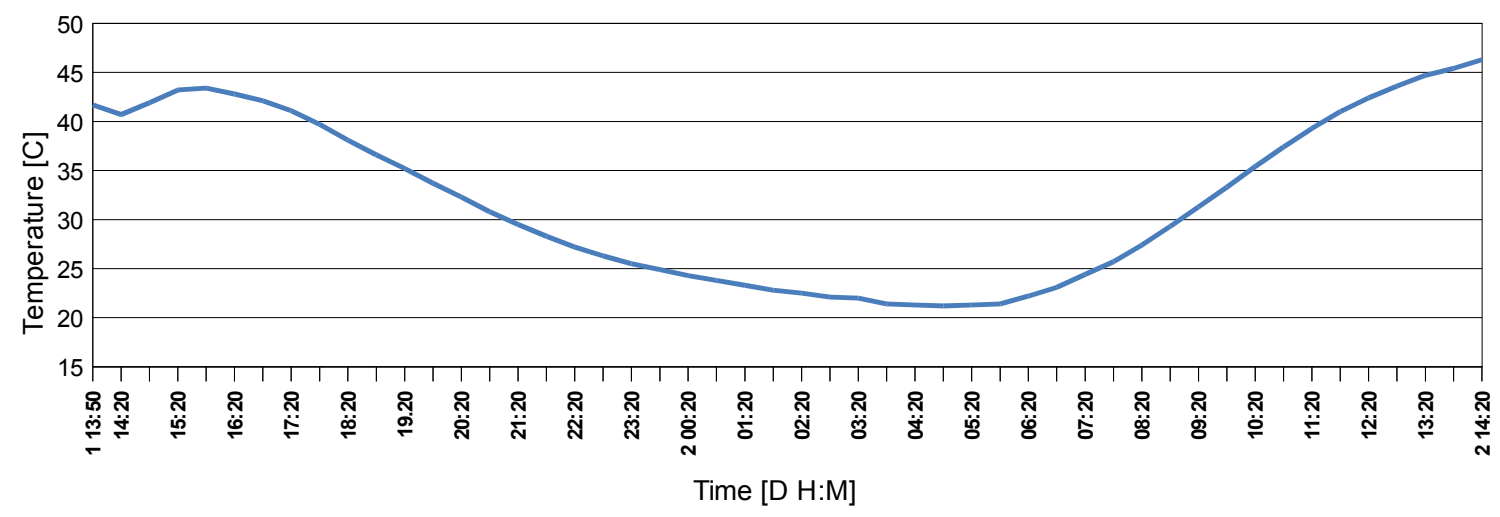

Fig. 10. Changes of temperature during measurement II 


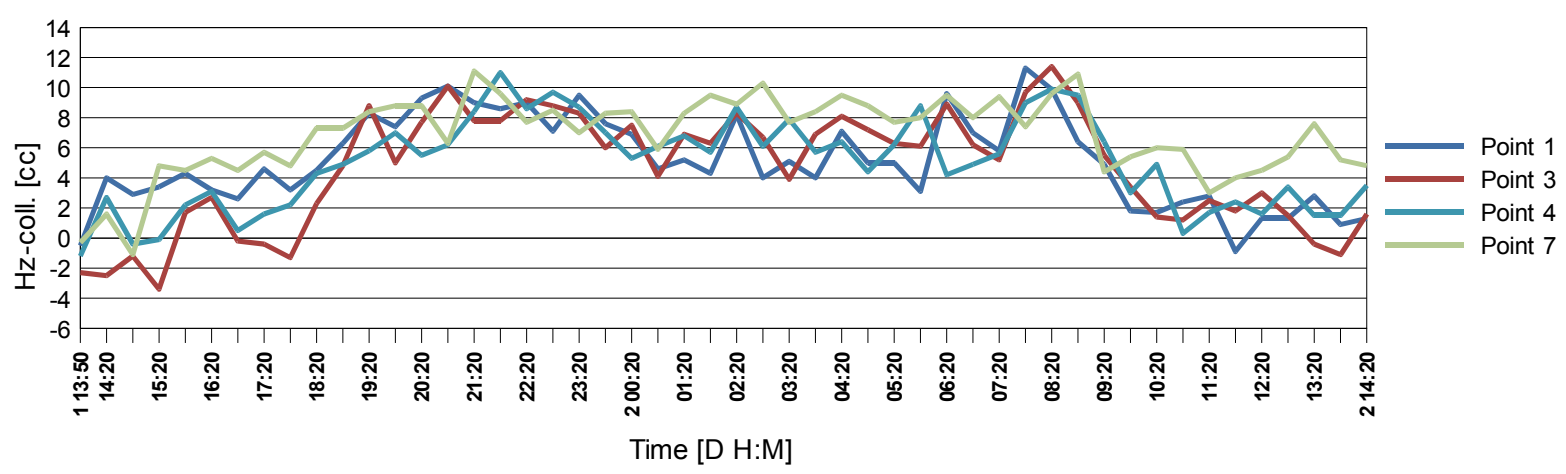

Fig. 11. Changes of Hz-collimation during measurement II

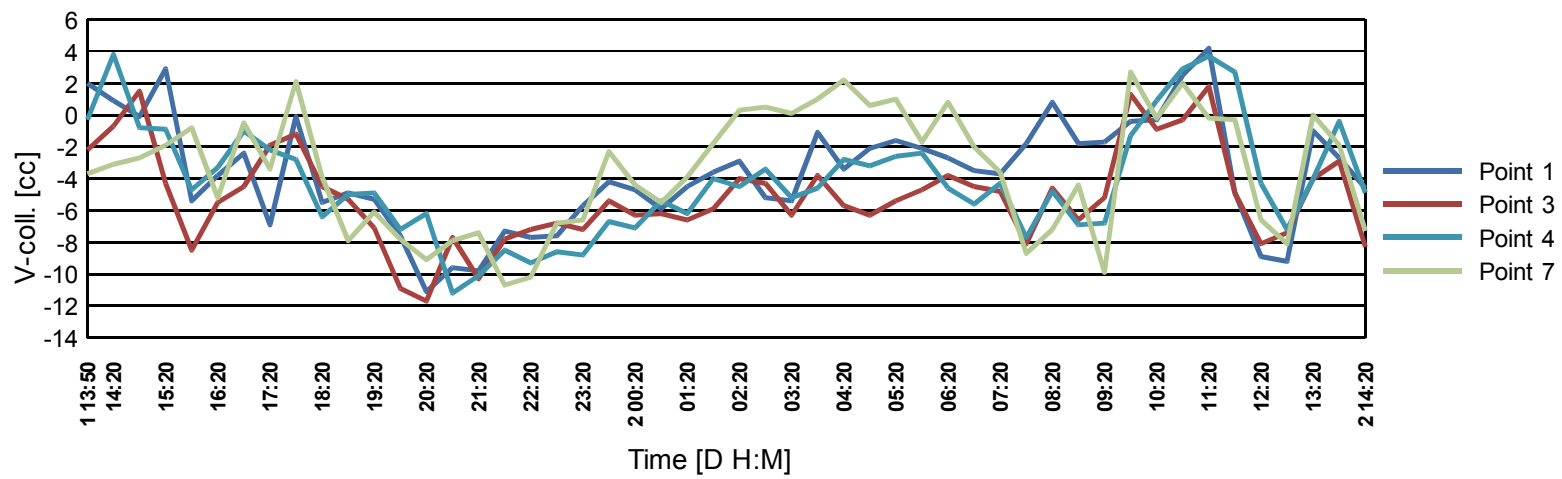

Fig. 12. Changes of $\mathrm{V}$-collimation during measurement II

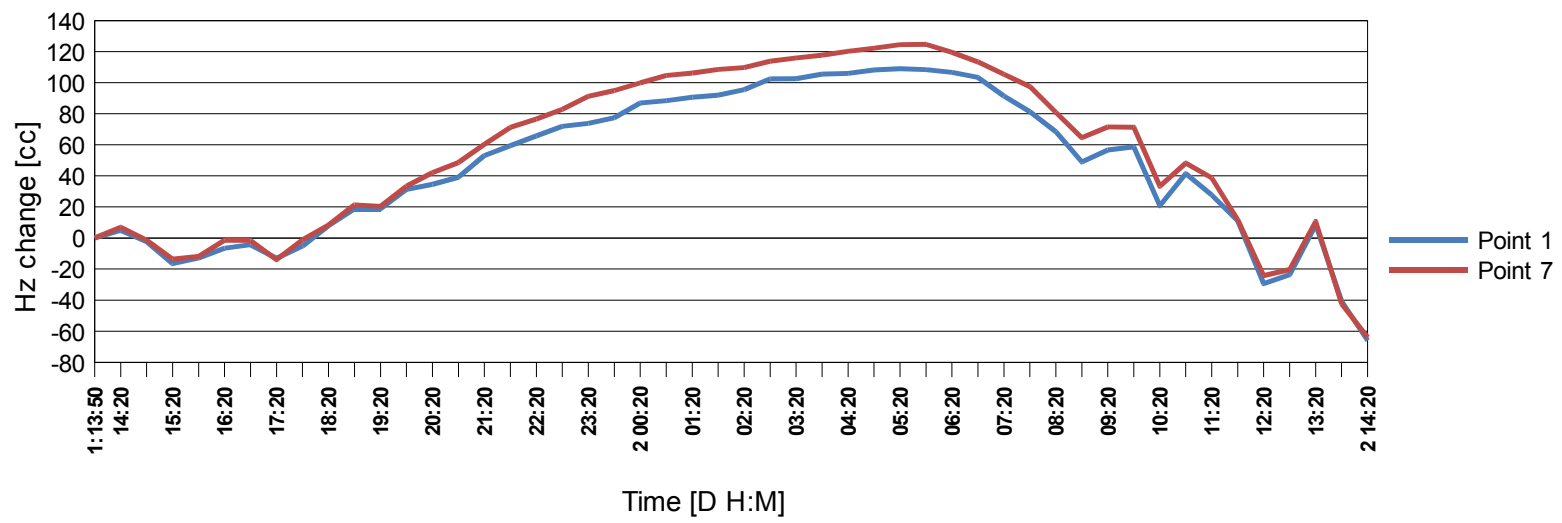

Fig. 13. Changes of instrument orientation during measurement II

Similarly to measurement I, we used Pearson correlation coefficient to determine the correlation between measured values and temperature. Results are presented on charts (fig. 14, 15 and 16).

Changes of Hz-collimation and V-collimation (Fig. 11 and 12) are much smaller than in the case of TDA5005 and only slightly exceed deviations of automatic aiming with ATR system. The changes are also (in comparison with TDA5005) less correlated with temperature. In the case of V-collimation, they seem to be not correlated at all (Fig 15).

The orientation of the instrument varied in a similar way as in measurement I. This time the temperature seems to be the main reason causing the changes. 


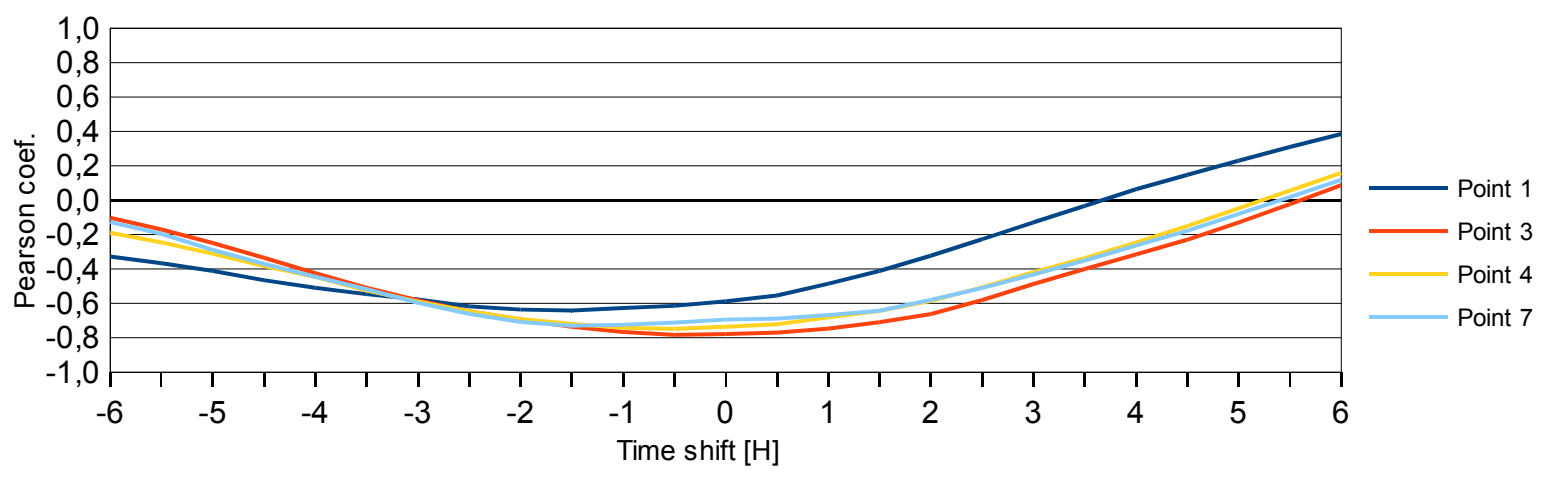

Fig. 14. Correlation between $\mathrm{Hz}$-collimation and temperature (Pearson coefficient)

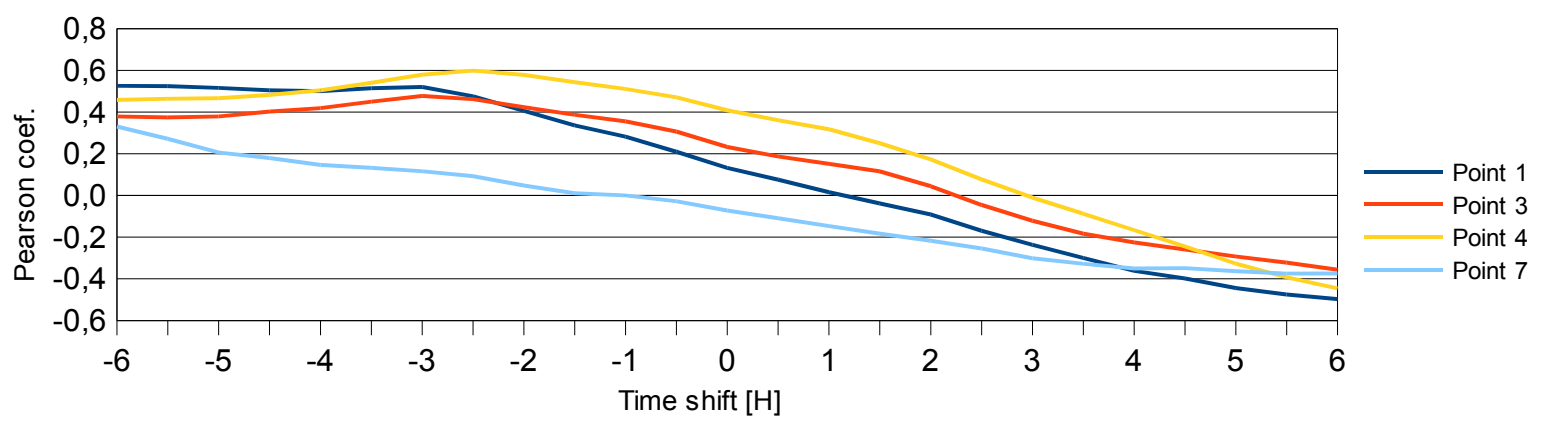

Fig. 15. Correlation between V-collimation and temperature (Pearson coefficient)

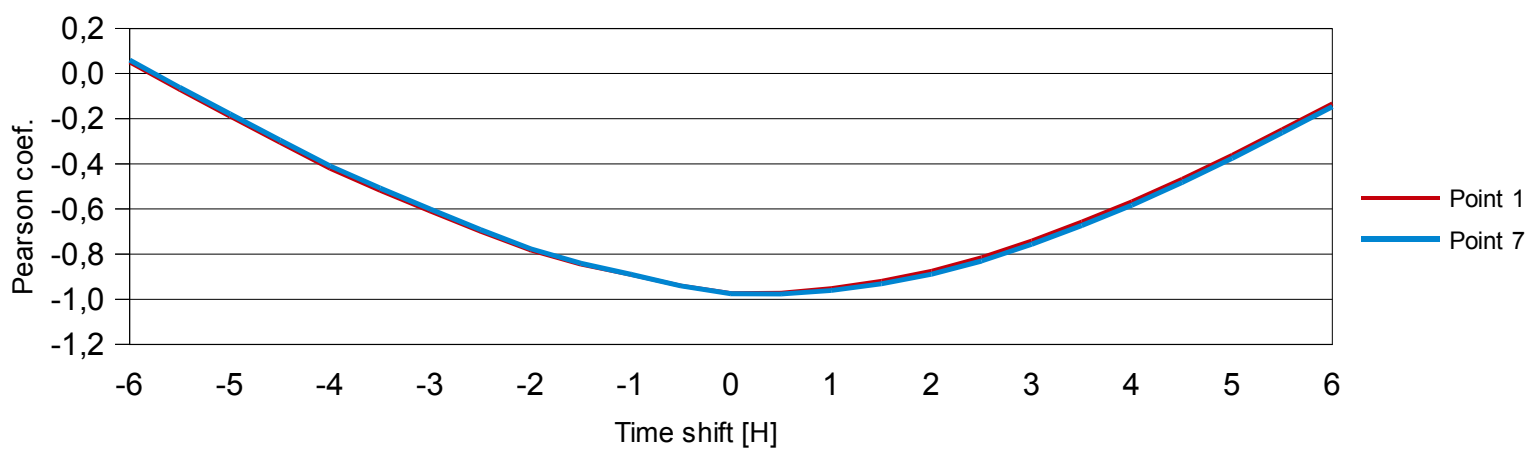

Fig. 16. Correlation between orientation changes and temperature (Pearson coefficient)

\section{Measurement III (TCRP1201+)}

The third measurement was made to test changes of instrument tilts and behaviour of instrument tilt compensation system. The measurement was taken during a 1-day session with the TCRP1201+. The temperature changed by $20.5^{\circ} \mathrm{C}$ (Fig. 17). To determine instrument tilts, compensation system readouts TL an TC were used. Readings were made in two faces and two perpendicular directions of the total station telescope. In such a way an instrument inclination in each direction (Tx and Ty) was determined twice using both compensation system readouts.

Changes in tilts (Fig. 18) appeared to be quite large and reached 14.5 mgon (Tx) and 27.2 mgon (Ty). Tilt changes are correlated with temperature (Fig. 19, 20) but in the case of Tx, a constant drift is visible - analogically as in the case of instrument orientation. 


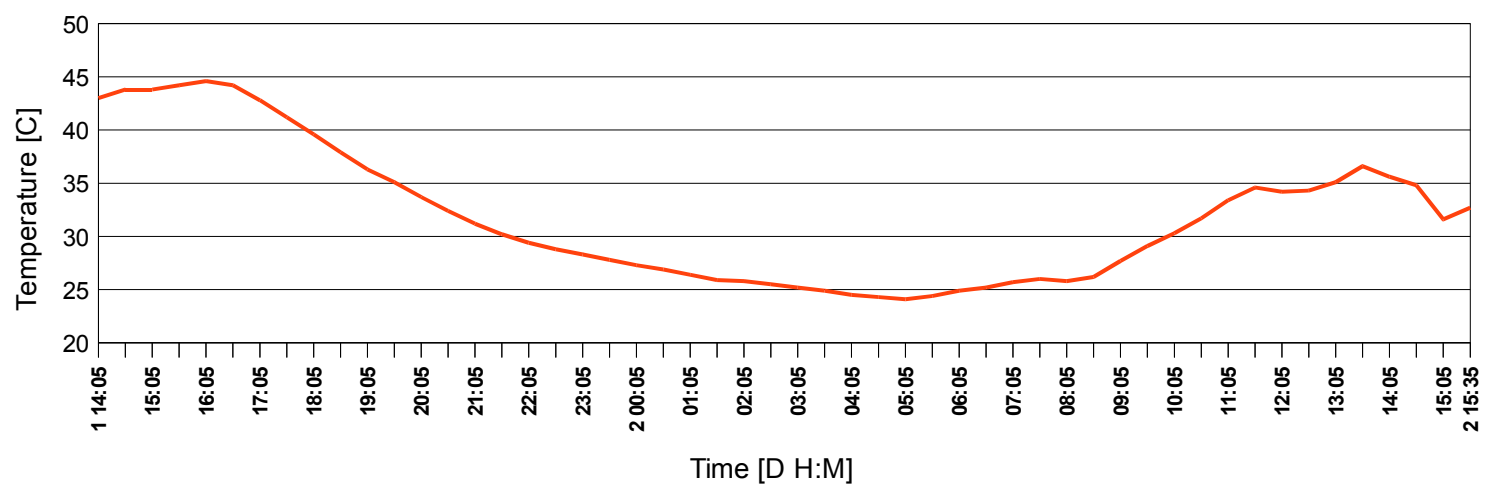

Fig. 17. Changes of temperature during measurement III

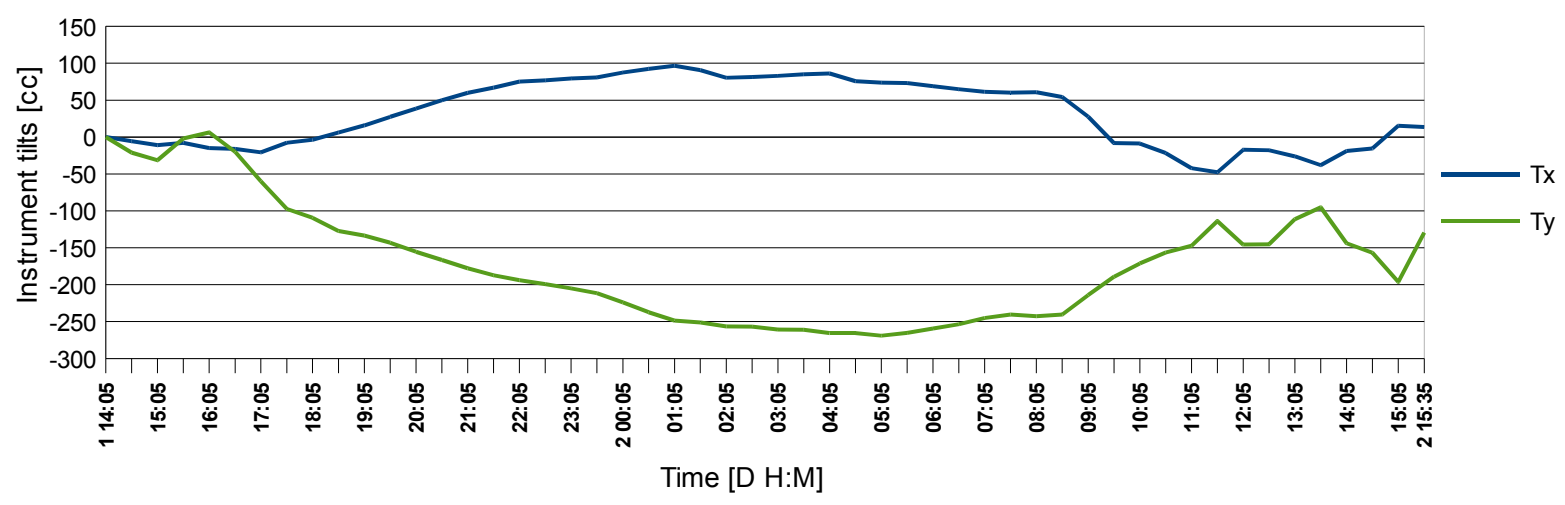

Fig. 18. Changes of instrument tilts during measurement III

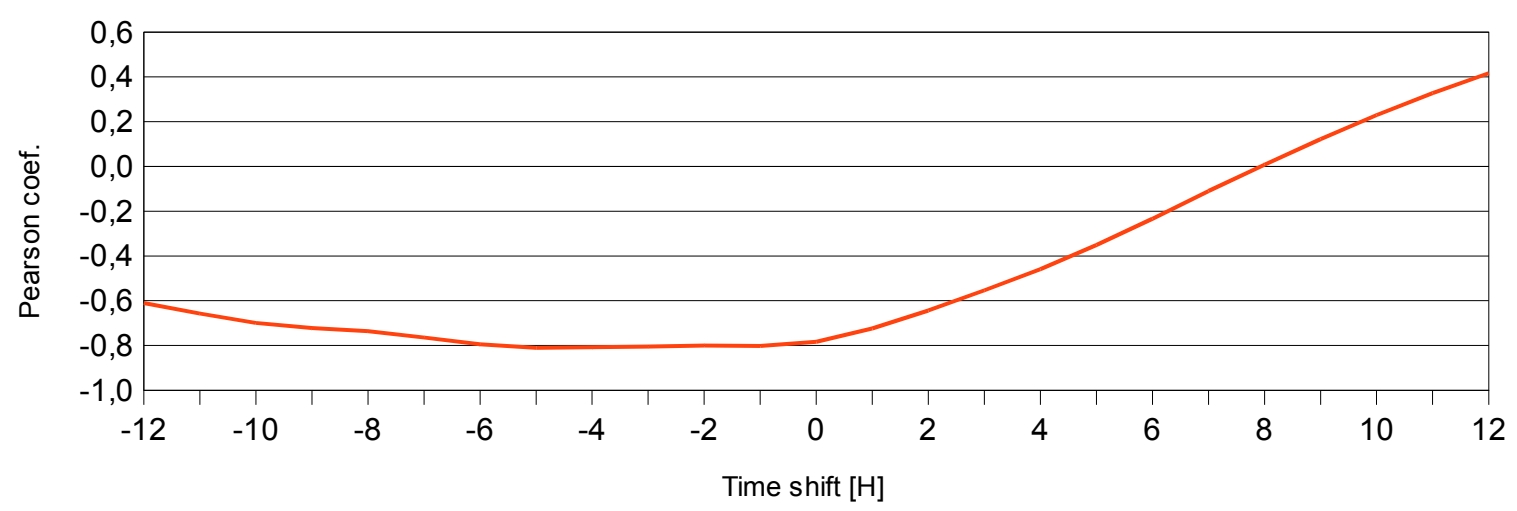

Fig. 19. Correlation between Tx and temperature during measurement III

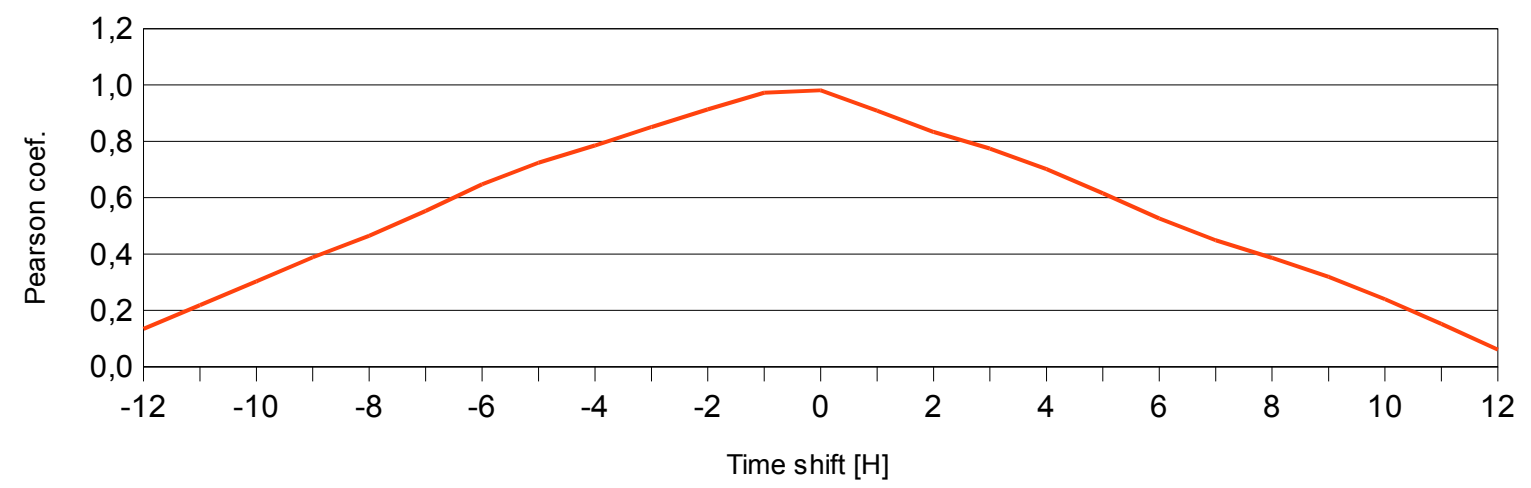

Fig. 20. Correlation between Ty and temperature 
Another task of measurement III was checking instrument tilt compensation system. Changes of compensation system state can be obtained by two faces measurement as it is described in (Raby P. 2001). We assumed: TL - along direction changes, TC - side direction changes. Changes of TL and TC are shown on Fig. 21.

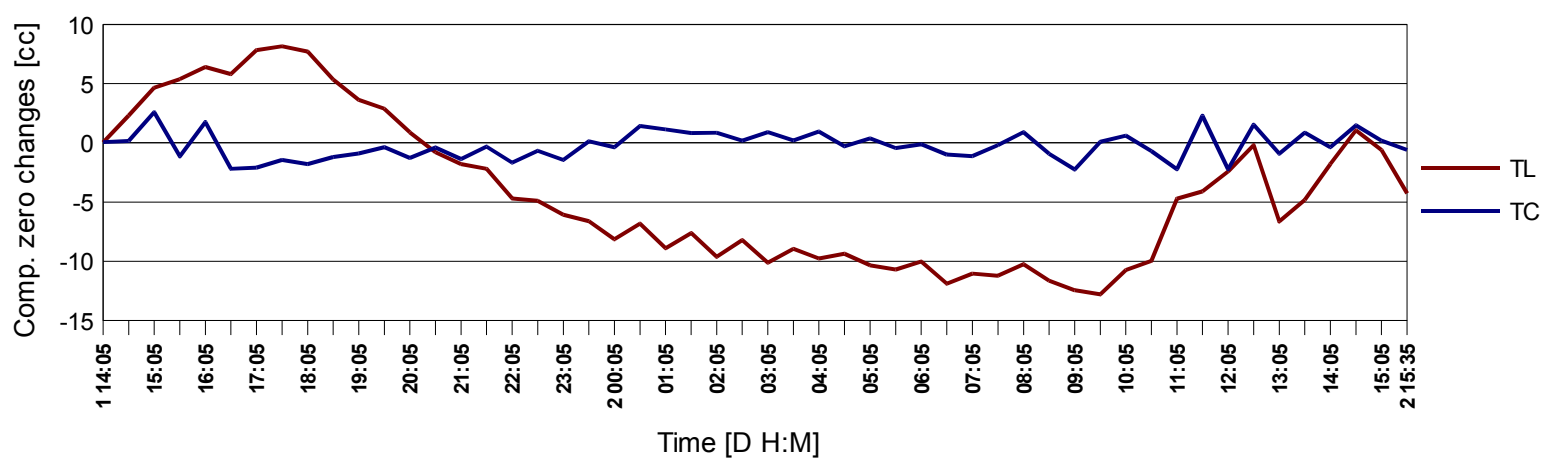

Fig. 21. Changes of tilt compensation system state

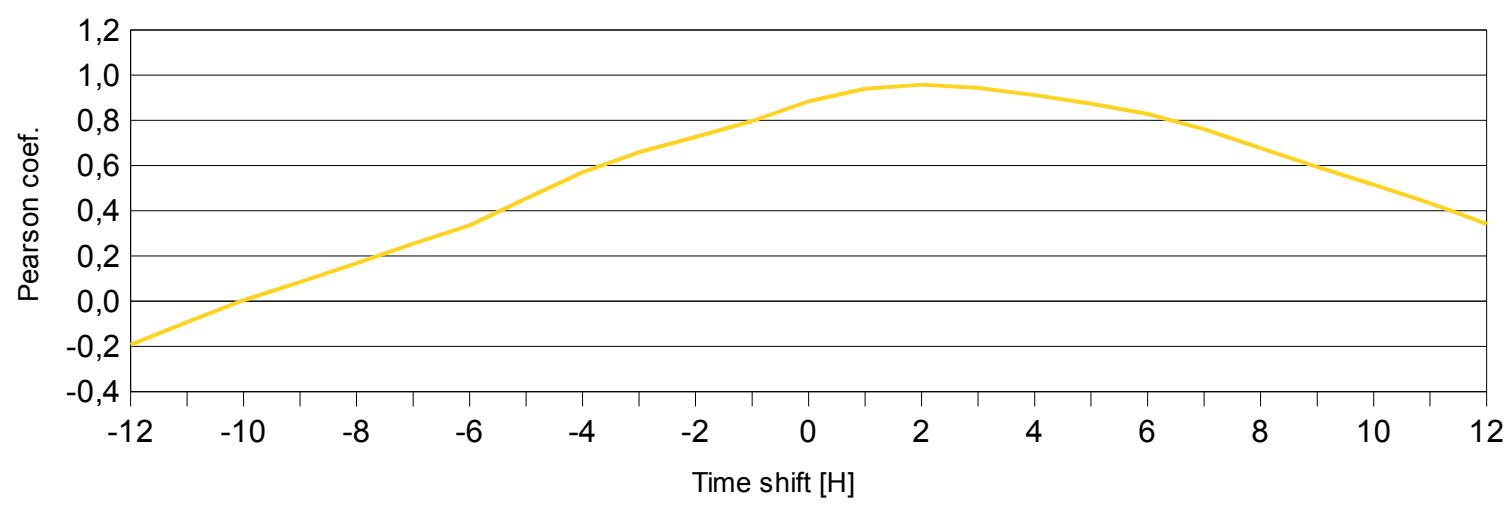

Fig. 22. Correlation between TL and temperature

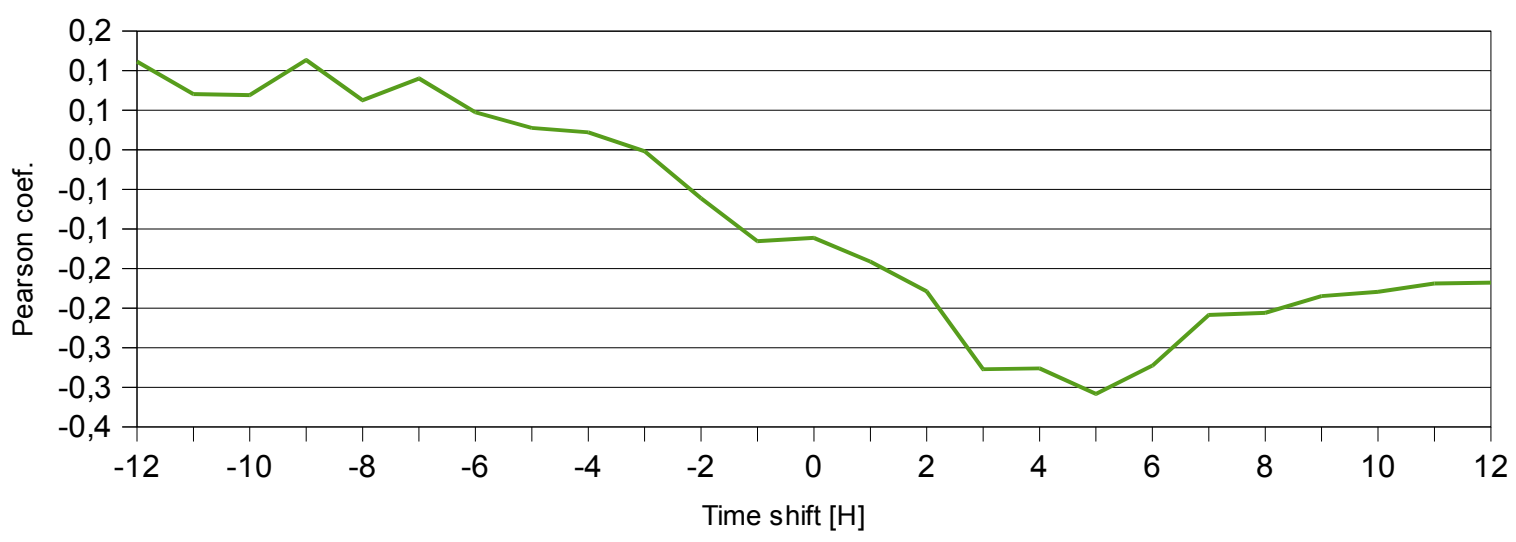

Fig. 23. Correlation between TC and temperature

Results of the investigations are even more interesting as only one direction of compensation system (TL) seem to be temperature sensitive. The changes in along direction are not large ( 2 mgon) but significantly exceed the accuracy of compensation. They are also noticeably correlated with temperature (Fig. 22). The side direction compensation works properly in the whole range of temperature. As the changes in compensation does not exceed accuracy of compensation they also doesn't show any correlation TC with temperature (Fig. 23). 


\section{Concluding remarks}

Analyses of the measurement results led to the conclusion that telescope of TDA5005 is very sensitive to ambient temperature. It refers, especially to the vertical plane and V-collimation. In the case of both $\mathrm{Hz}$-collimation and V-collimation, there is a visible correlation with temperature.

TCRP1201+ is much less sensitive to temperature changes. However, it does not change the fact, that its nominal accuracy is worse than TDA5005. Analysing charts of $\mathrm{Hz}$ - and V-collimation two critical points can be realised. The first corresponds with time about 21:00, the second with time about 8:30 of the next day. In both cases, we can see a change of trend of analysed value. Comparing charts of instrument error changes with temperature chart it can be noted, that points of critical instrument error change are not directly correlated with temperature changes. More likely explanation of this course of changes seems to be the direct illumination of the instrument with sunlight, which affected work of the ATR system. Because the exact moment of sunrise and sunset were not recorded during the measurements, checking this hypothesis require further research.

Changes of Hz-orientation were investigated two times (with TDA5005 and TCRP1201+) and appeared to be great (40 mgon and $12 \mathrm{mgon}$ ). The greater values were measured with TDA5005. They can be connected as a stand twists and depend on stand quality and construction. Therefore they should not be generalized. In our case the difference in stand twist can be caused by greater weight of TDA5005.

On the grounds of conducted measurements analysis, following conclusions can be drawn:

- High ambient temperature changes must be taken into consideration of instrumental errors. It especially refers to $\mathrm{Hz}$-collimation and V-collimation. Changes of tilt compensation system state are smaller but remarkable. When it is possible, measurement should be done in two faces of instrument. Such a method allows to eliminate $\mathrm{Hz}$ - and $\mathrm{V}$-collimation from measurement results.

- To keep constant instrument orientation during long term monitoring measurements, an instrument should be mounted on the heavy, stable tripod.

- In case of using standard tripods, a cyclic orientation checks are necessary. It should be done by performing additional direction measurements to fixed reference points.

\section{References}

Raby P. (2001): Tilt prediction for total station, U.S. Patent No. 6,243,658. Washington, DC: U.S. Patent and Trademark Office.

Michel V., Person T., Kasser M. (2003): 74 Motorized Tacheometers Aiming at 5350 Prisms in Amsterdam: The Largest Topometric Continuous Real Time Monitoring System in the World?, Surveying in Industry and Construction FIG Working Week Paris, France, April 13-17, 2003

Depenthal C. (2004). Stativbewegungen bei der Verwendung von Robottachymetern. Allgemeine Vermessungs-Nachrichten 6/2004, pp 227-233.

Woźniak M. (2006): Investigation of using total station with ATR system in monitoring of displacements, Reports on Geodesy, No. 1(76) 2006 pp. 221-226

Kirschner H., Stempfhuber W. (2008): The Kinematic Potential of Modern Tracking Total Stations - A State of the Art Report on the Leica TPS1200+, Proceedings of 
the 1st International Conference on Machine Control \& Guidance, June 24-26 Zurich Switzerland pp. 51-60

Woźniak M., Odziemczyk W., Jastrzębski S., Wojciechowski J. (2008): Ivestigation of short-term roof structure deformations using geodetic methods, Reports on Geodesy, No. 1(84) 2008 pp. 105-110

Odziemczyk W., Woźniak M. (2008): TC-calc jako system zdalnego monitoringu geodezyjnego. Gliwice 2008, Wykorzystanie metod geodezyjnych w ocenie stanu geometrycznego budowli, TC-calc as a system of remote geodetic monitoring. Utilisation of geodetic methods in the assessment of geometric conditions of structures, Praca zbiorowa pod redakcją K. Kłoska i W. Prószyńskiego, Wydawnictwo Politechniki Śląskiej, pp. 173-180

Odziemczyk W., Woźniak M. (2009): Monitoring of WUT grand hall roof in conditions of high temperature changes, Reports on Geodesy, No. 1(85) 2009

Gottwald, R., Muller, L., \& Obrist, M. (2011): Leica TDA5000-Short Range Performance Tests using Corner Cube and Tooling Ball Reflectors. FHBB Basel Institute of Technology, Switzerland Dept. of Surveying \& Geoinformation Systems.

Odziemczyk W. (2012): Automatyzacja procedur pomiarowych realizowanych tachimetrami systemu Leica TPS1200. Automation of measuring procedures performed using Leica TPS1200 system total stations. Poznań 2012, Inżynieryjne Zastosowania Geodezji, Ed. A. Plichty and I. Wyczałka, Wydawnictwo Politechniki Poznańskiej, pp. 95 - 102

Odziemczyk W. (2014): Analysis of deformations of the skylight construction at the main hall of The Warsaw University of Technology, Reports on Geodesy and Geoinformatics vol. 97/2014; pp. 35-46

\section{Authors:}

Ph. D. Waldemar Odziemczyk 1), waldemar.odziemczyk@pw.edu.pl

Assoc. Prof. Marek Woźniak ${ }^{1)}$, marek.wozniak@pw.edu.pl

1) Faculty of Geodesy and Cartography

Warsaw University of Technology

PI. Politechniki 1, 00-661 Warsaw, Poland 